OPEN ACCESS

Edited by:

Colleen B. Jonsson University of Tennessee Health

Science Center (UTHSC),

United States

Reviewed by:

Julià Blanco,

IrsiCaixa, Spain

Yucel Aydin,

Tulane University, United States

*Correspondence: Tingtao Chen chentingtao1984@163.com

Specialty section:

This article was submitted to

Virus and Host

a section of the journal Frontiers in Cellular and Infection Microbiology

Received: 08 February 2019 Accepted: 17 July 2019 Published: 31 July 2019

Citation

Tian P, Wang Y, Liu H, Yang Y, Wu X, Wei $H$ and Chen T (2019) Preparation and Evaluation of the Fully Humanized Monoclonal Antibody GD-mAb Against Respiratory Syncytial Virus. Front. Cell. Infect. Microbiol. 9:275. doi: 10.3389/fcimb.2019.00275

\section{Preparation and Evaluation of the Fully Humanized Monoclonal Antibody GD-mAb Against Respiratory Syncytial Virus}

\author{
Puyuan Tian ${ }^{1}$, Yuqing Wang ${ }^{1}$, Hui Liu ${ }^{1}$, Yulu Yang ${ }^{1}$, Xiaoli Wu ${ }^{2}$, Hua Wei ${ }^{3}$ and \\ Tingtao Chen ${ }^{1 *}$ \\ ${ }^{1}$ National Engineering Research Center for Bioengineering Drugs and the Technologies, Institute of Translational Medicine, \\ Nanchang University, Nanchang, China, ${ }^{2}$ JiangXi University of Traditional Chinese Medicine, College of Basic Medicine, \\ Nanchang, China, ${ }^{3}$ State Key Laboratory of Food Science and Technology, Nanchang, China
}

Respiratory syncytial virus (RSV) is the major cause of pulmonary and bronchial inflammation in infants, young children, and immunocompromised adults, but therapeutic options to control RSV are limited. In the present study a single chain antibody against RSV (GD-scFv) was screened using phage display library panning technology and a full-length monoclonal antibody (GD-mAb) was developed from GD-scFv based on the sequence encoding $\lg \mathrm{V}_{\mathrm{H}}$ and $\lg \mathrm{V}_{\mathrm{L}}$. The anti-RSV potential of GD-mAb was evaluated in vitro and in mice. Our results indicated that both GD-scFv $(4.25 \pm 2 \mathrm{nM})$ and GD-mAb $(3.13 \pm 0.89 \mathrm{nM})$ showed high binding capability and strong binding specificity to GD protein. GD-mAb effectively neutralized RSV and reduced the plaque number in a concentration-dependent manner through a plaque reduction neutralization assay. In mice, GD-mAb lowered the lung index and reduced the lung virus titer in the mouse lung $(p<0.05)$. Antibody treatment reduced the phosphorylated protein level in pathways of TLR4/NF-кB, MAPKs, and PI3K/Akt $(p<0.05)$ and correlated with an absence of pro-inflammatory factors TNF- $\alpha, \mathrm{IL}-1 \beta$, and IL- 6 in the mouse lung and serum $(p<0.05)$. In summary, these data suggest that GD-mAb may be an effective therapeutic agent for the treatment of RSV infections.

\section{Importance}

Currently, only a few therapeutic options are available to control respiratory RSV in humans. In this study, our group developed a full-length monoclonal antibody (GD-mAb) and reported a high binding specificity of the RSV surface glycoproteins G. Moreover, GD-mAb effectively neutralized RSV in vitro, and significantly lowered the lung index and reduced the lung virus titer in an infected mouse lung, which suggests that GD-mAb may serve as an effective antiviral agent for RSV infection.

Keywords: respiratory syncytial virus (RSV), phage display technology, monoclonal antibody, inflammation, signal pathway 


\section{INTRODUCTION}

A member of the Paramyxoviridae, respiratory syncytial virus (RSV) is regarded as the leading cause of viral lower respiratory tract infection in infants and young children worldwide (Weinberg, 2017). Studies indicate that RSV causes 33,100,000 episodes, 3,200,000 hospital admissions, and 59,600 in-hospital deaths each year in children younger than 5 years of age (Shi et al., 2017; Weinberg, 2017). To date, vaccination against RSV has been unsuccessful in young children, because of their immature immune system (Tripp, 2004; Fauci et al., 2008; Haynes et al., 2009). However for infants with a high risk of serious disease, the neutralizing antibodies motavizumab and palivizumab may be used (DeVincenzo et al., 2014; Murray et al., 2014). It is important to note that these antibodies therapeutics are not effective for the treatment of an active infection (Fauci et al., 2008) and for immune compromised patients (Varga and Braciale, 2002).

In previous studies, three glycoproteins (F, G, and $\mathrm{SH}$ ) have been proven to play important roles in triggering a host protective immune response (Fauci et al., 2008; McLellan, 2015; Tian et al., 2018). The G protein is recognized as an important neutralizing antigen in inducing and modulating the host immune response to RSV infection (Murawski et al., 2010; Tian et al., 2018). Our group has evaluated the effect of truncated G protein (GD) delivered by live attenuated Salmonella as a vaccine against RSV, which represents a promising approach to protect the host against RSV (Tian et al., 2018). In the present study our group isolated a single chain antibody (GD-scFv) from a phage display library by panning the GD protein. We engineered the variable region of its heavy chain and the variable region of the light chain into the corresponding vectors (IgG and Igא) to develop the full-length monoclonal antibody (GD-mAb) and evaluated its protective efficacy against RSV both in vitro and in mice.

\section{METHODS}

\section{Construction and Preliminary Screening of Single-Chain Antibody Fragment (scFv) Phage Antibody Library}

The products of the scFv antibody gene library were inoculated into SB-A+ liquid medium (containing $100 \mathrm{mg} / \mathrm{L}$ ampicillin), incubated with shaking to $\mathrm{OD}_{600}$, reaching $0.9-1$ at $37^{\circ} \mathrm{C}$, and helper phage M13K07 $\left(4 \times 10^{10} \mathrm{pfu} / 100 \mathrm{~mL}\right)$ and kanamycin $(70 \mathrm{mg} / \mathrm{L})$ were added. After overnight culturing in SB-A+K+ liquid medium (containing $100 \mathrm{mg} / \mathrm{L}$ ampicillin and $70 \mathrm{mg} / \mathrm{L}$ kanamycin), it was centrifuged $\left(8,000 \mathrm{~g}\right.$ for $15 \mathrm{~min}$, at $\left.4^{\circ} \mathrm{C}\right)$ and the phage antibodies in the supernatant were precipitated with $80 \mathrm{~g} / \mathrm{L}$ PEG 8000 and $60 \mathrm{~g} / \mathrm{L} \mathrm{NaCl}$, and resuspended in PBS (containing $1 \%$ BSA and $10 \%$ glycerin). After centrifugation, the supernatants were obtained and the scFv phage antibody library was constructed and plated. The purified GD protein was coated in a 96-well plate overnight at $4^{\circ} \mathrm{C}$. The next day, plates were washed with PBS, blocked with 5\% BSA-PBS and incubated for $1 \mathrm{~h}$ at $37^{\circ} \mathrm{C}$. The phagemid populations were added to the plate, and after incubation for $2 \mathrm{~h}$ at $37^{\circ} \mathrm{C}$ the plate was emptied and washed with $0.5 \%$ PBST (containing $0.5 \%$ Tween 20 ) five times. Log phase Escherichia coli XL1-Blue (E. coli TG1) and M13K07 were then added. The phages were re-infected and were rescued after a $2 \mathrm{~h}$ incubation at $37^{\circ} \mathrm{C}$. The panning process was repeated for four times.

\section{Isolation and Verification of the Affinity and Specificity of GD-scFv}

In collaboration with Beijing Gegen Biotechnology Co., Ltd. (Beijing, China), we obtained the variable regions of the light chain $\left(V_{L}\right)$ genes and variable regions of the heavy chain $\left(V_{H}\right)$ genes, from the phage antibody library, using GD protein as antigen (Tian et al., 2018). The genes of $\mathrm{V}_{\mathrm{H}}$ and $\mathrm{V}_{\mathrm{L}}$ were engineered into vector pET-28a with a linker, and the protein GD-scFv was expressed using E. coli BL21. Ni-NTA affinity chromatography was applied here to purify GD-scFv (with a His tag) from periplasmic lysates, and its purity and molecular weight were tested using SDS-PAGE method.

The GD protein was then coated in the bottom of 96well ELISA plates overnight at $4^{\circ} \mathrm{C}$, and tenfold seriallydiluted antibodies were prepared in $10 \%$ FBS and were added into the antigen-coated plates for $1 \mathrm{~h}$ at $37^{\circ} \mathrm{C}$. Plates were washed three to five times with TBST and $100 \mu \mathrm{l} 1: 1,000$ diluted anti-His antibody (Cell Signaling Technology, 2365P) was then added and was incubated for $1 \mathrm{~h}$ at $37^{\circ} \mathrm{C}$. Plates were washed three to five times with TBST, and the second antibody with HRP was used. TMB substrate was used as the substrate for color development and plates were read at $450 \mathrm{~nm}$.

To test the degree of specificity of GD-scFv, an irrelevant IgG (Bethyl Laboratories, A80-104P) was used as the antigen, and coated in the bottom of 96-well ELISA plates to test the non-specific affinity of GD-scFv. Kd was calculated by the equation $\mathrm{Kd}=2\left[\mathrm{Ab}^{\prime}\right]_{\mathrm{t}}-[\mathrm{Ab}]_{\mathrm{t}}$, where $\left[\mathrm{Ab}^{\prime}\right]_{\mathrm{t}}$ refers to the $s c F v$ concentration at $\mathrm{OD}_{450}$ for the half concentration of GD protein coated wells, while $\left[\mathrm{Ab}^{\prime}\right]_{\mathrm{t}}$ refers to the $\mathrm{scFv}$ concentration at $\mathrm{OD}_{450}$ for the full-strength concentration of GD protein coated wells.

\section{Construction and Verification of the Affinity and Specificity of GD-mAb}

Genes encoding Ig $\mathrm{V}_{\mathrm{H}}$ and $\mathrm{Ig} \mathrm{V}_{\mathrm{L}}$ from GD-scFv were cloned into IgG heavy- and light-chain expression vectors (IgG and Igא), the GD-mAb was expressed by transfection of $293 \mathrm{~T}$ cells and was purified as described previously (Tiller et al., 2008; Huang et al., 2013). The GD protein and irrelevant IgG (Bethyl Laboratories, A80-104P) were then coated in the bottom of 96well ELISA plates to test the affinity and degree of specificity of GD-mAb.

\section{Evaluation of the Neutralization Effect of GD-mAb on RSV in vitro}

Vero cells (African green monkey kidney fibroblasts, Chinese Academy of Sciences Cell Bank, GNO10) were serially passaged in Dulbecco's Modified Eagle Medium (DMEM) (Gibco BRL, Grand Island, NJ, USA) supplemented with 5\% fetal bovine serum (FBS, Gibco BRL, Grand Island, NJ, USA), 100 units of penicillin G, $100 \mathrm{mg} / \mathrm{mL}$ of streptomycin, $0.2 \%$ sodium bicarbonate, and $2 \mathrm{mM}$ L-glutamine. The RSV long 
strains (kindly donated by Dr. Xiaoming Liang, Boya Biology Co., Ltd.) were passaged more than three times in Vero cells in our laboratory and the virus stocks were stored at $-80^{\circ} \mathrm{C}$.

GD-mAb was diluted in DMEM containing 10\% FBS at different concentrations with 50 PFU of RSV and incubated for $1 \mathrm{~h}$ at $37^{\circ} \mathrm{C}$. The mixture was then added into 12 -well plates at $2 \times 10^{4}$ cells/well and incubated at $37^{\circ} \mathrm{C}$ for $45 \mathrm{~min}$. The cells were then washed and DMEM containing 1\% methylcellulose was added, the cells were incubated at $37^{\circ} \mathrm{C}$ for 4 days and fixed with $10 \%$ formaldehyde for $30 \mathrm{~min}$. Finally, hematoxylin and eosin were used to count the white plaques on the wash plate.

\section{Animal Study}

Eight-week-old female BALB/c mice, provided by Hunan Silaike Jingda Laboratory Animal Co., Ltd. (Changsha, Hunan, China), were kept in the animal facility under standard conditions (humidity $50 \pm 15 \%$, temperature $22 \pm 2^{\circ} \mathrm{C}, 12 / 12$ light-dark cycle) and were fed a standard diet. The animals were randomized into eight groups ( $n=14$ per group). Three mice were sacrificed on day 3 for viral titer tests only, eight mice were sacrificed on day 7 for all the tests; three mice were sacrificed on day 11 for viral titer tests only. The eight groups were: (1) the control group (C); (2) the group challenged with RSV (M); (3) the group pretreated with purified GD-mAb $(3 \mathrm{mg} / \mathrm{kg})$ and then challenged with RSV (PH); (4) the group pre-treated with purified GD-mAb $(1.5 \mathrm{mg} / \mathrm{kg}$ ) and then challenged with RSV (PL); (5) the group challenged with RSV and then treated with ribavirin $(0.05 \mathrm{~g} / \mathrm{kg}$ per day, H20056707, Sichuan Baili Pharmaceutical Co., Ltd.) (R); (6) the group challenged with RSV and then treated with purified GD-mAb (0.032 mg/kg) (TL); (7) the group challenged with RSV and then treated with purified GD-mAb $(0.16 \mathrm{mg} / \mathrm{kg})(\mathrm{TM}) ;(8)$ the group challenged with RSV and then treated with purified GD-mAb (0.32 mg/kg) (TH). Mice received $10^{7} \mathrm{PFU} / \mathrm{mL}$ RSV $(100 \mu \mathrm{l})$ after fluorothane anesthesia for 3 days, and purified GD-mAb was injected intravenously at a specific time. After inoculation, the mice were killed, and the lungs were removed for further analysis.

The present study was approved by the Ethical Committee of the Second Affiliated Hospital of Nanchang University (Nanchang, China) and all methods were performed in accordance with the approved guidelines.

\section{Lung Index}

After the final exposure to the RSV infection described in section Animal Study, mice were weighed sacrificed, and the whole lung was taken from the chest. Lung tissue was rinsed twice with precooled physiological saline and then surface water was dried and the lungs were weighed. Lung index $=[$ lung weight $(\mathrm{g}) /$ body weight $(\mathrm{g})] \times 100 \%$.

\section{Viral Titers}

Viral titers in the lungs of RSV-infected mice were determined as described elsewhere (Haynes et al., 2002). Briefly, lungs were aseptically removed from the mice on days 3, 7, and 11 after infection and were stored at $-80^{\circ} \mathrm{C}$ until assayed. Lungs were weighed and individual lung samples were homogenized in $1 \mathrm{ml}$ of cold, sterile PBS, and tenfold serial dilutions (in serumfree DMEM) of the lung homogenates were added to confluent Vero cell monolayers in 12-well plates. After adsorption for $1 \mathrm{~h}$ at $37^{\circ} \mathrm{C}$, cell monolayers were overlaid with tissue culture DMEM containing 1\% methylcellulose (Sigma, Chem- ical Co.), incubated at $37^{\circ} \mathrm{C}$ for 4 or 5 days, and viral plaque formation was enumerated using hematoxylin and eosin staining.

\section{Histopathological Analysis}

The excised samples of the lungs were fixed in $4 \%$ paraformaldehyde, embedded in paraffin and processed for histopathological analysis. All samples were cut into $5 \mu \mathrm{m}$ sections, rehydrated with xylene and declining grades of ethanol for $5 \mathrm{~min}$, and washed three times using PBS for another $5 \mathrm{~min}$, the lung slides were used for hematoxylin and eosin (H\&E) staining. A histopathological evaluation was performed to evaluate the integrity of the alveolar structure, the infiltration of the alveolar cavity and interstitial inflammatory cells, by a histopathologist with no prior knowledge of the identity of the samples.

\section{Western Blot Analysis}

Lung tissues were homogenized and extracted using normal sodium, and then centrifuged at $8,000 \mathrm{~g}$ for $25 \mathrm{~min}$. Protein concentrations were measured and proteins were resolved using SDS (sodium dodecyl sulfate) polyacrylamide gel electrophoresis (Hu et al., 2016; Zeng et al., 2017). Then proteins were electro transferred to polyvinylidene difluoride membranes and blocked using 5\% bovine serum (BSA) in TBST for $1.5 \mathrm{~h}$ at RT. Membranes and primary antibodies were then coincubated overnight at $4^{\circ} \mathrm{C}$, washed with TBST buffer, and then appropriate amounts of secondary antibody conjugated with HRP were added for another $1 \mathrm{~h}$, at RT. Primary antibodies antimouse $\beta$-actin (1:1,000; Cell Signaling Technology, 4970S), anti-mouse NF-kB (1:1,000; Cell Signaling Technology, 8242S), anti-mouse TLR4 (1:1,000; Santa Cruz Biotechnology, sc293072), anti-mouse p-p38 (1:1,000, CapitalBio Corporation, bs5477R), anti-mouse p-ERK (1:2,000, Cell Signaling Technology, 4370), anti-mouse PI3K (1:1,000, CapitalBio Corporation, bs-5570R), and anti-mouse p-AKT (1:2,000, Cell Signaling Technology, 4060) were used in the present study.

\section{RNA Preparation and Quantitative PCR}

For the evaluation of cytokine mRNA expression levels, total RNA from the lung was prepared by adding TRIzol reagent (Gibco BRL, Grand Island, NJ, USA) according to the manufacturer's protocol. Total RNA of the samples was extracted, and the purity was tested using a NanoDrop 2000 spectrophotometer (Thermo Fisher Scientific) and $1 \mu \mathrm{g}$ of total RNA from each group was reverse transcribed to cDNA using a commercially available kit (Takara). Quantitative real-time PCR was performed with the $7900 \mathrm{HT}$ fast realtime PCR system $(\mathrm{ABI})$ using $2 \times$ SYBR Green master mix (Takara). The relative expression levels of the target genes were analyzed using the $2^{-\Delta \Delta \mathrm{Ct}}$ method for polymerase activation 

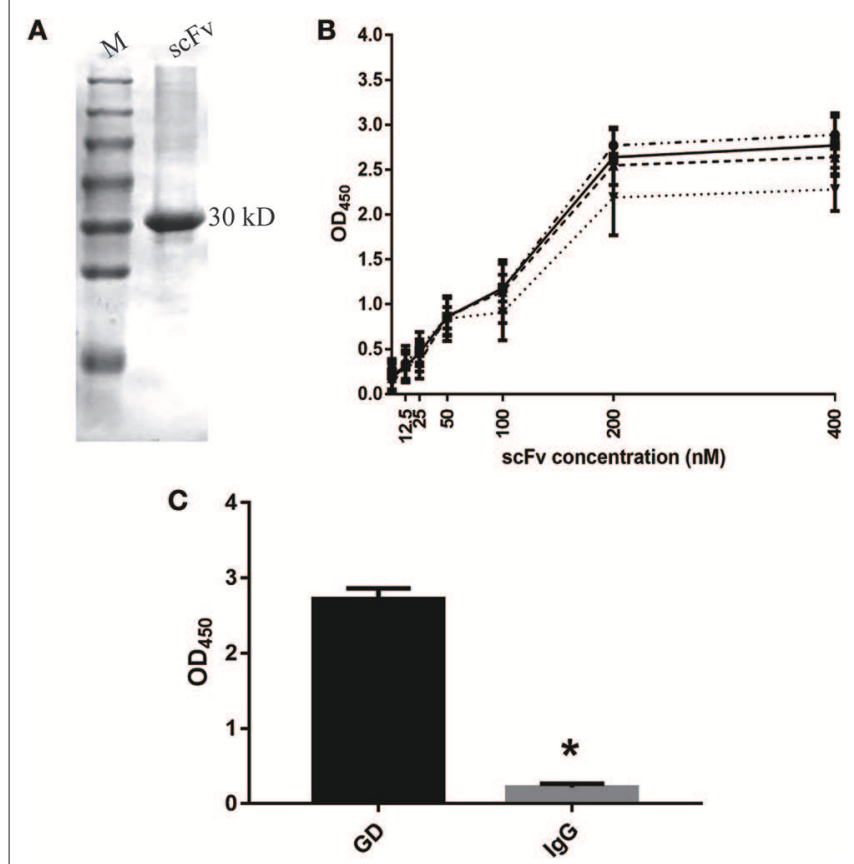

FIGURE 1 | Characteristics of GD-scFv isolated from phage display libraries. (A) The purity and molecular weight of GD-scFv using SDS-PAGE (30 kDa). (B) Measurement of the Kd between GD- scFv using ELISA. The calculated Kd for scFv-GD was $6.25 \mathrm{nM}$ using antigen concentrations of $2 \mu \mathrm{g} / \mathrm{ml}(-\cdot$.$) and$ $1 \mu \mathrm{g} / \mathrm{ml}(-), 4.72 \mathrm{nM}$ using antigen concentrations of 1 and $0.5 \mu \mathrm{g} / \mathrm{ml}(---)$, or $2.15 \mathrm{nM}$ using antigen concentration of 0.5 and $0.25 \mu \mathrm{g} / \mathrm{ml}$ (...). (C) Evaluation of the specificity of ScFv-GD using ELISA method. Results are presented as the mean $\pm \mathrm{SD} .{ }^{*} P<0.05$ vs. control group.

with the following primers (Q-PCR IL-1 $\beta$ : sense primer $5^{\prime}$ GTGTCTTTCCCGTGGACCTTC- ${ }^{\prime}$, antisense primer $5^{\prime}$ -TCATCTCGGAGCCTGTAGTGC-3'; Q-PCR TNF- $\alpha$ : sense primer $5^{\prime}$-GTGGAACTGGCAGAAGAGGCA-3', antisense primer $5^{\prime}$-AGAGGGAGGCCATTTGGGAAC-3'; Q-PCR IL-6: sense primer $5^{\prime}$ - GAAATCGTGGAAATGAG-3', antisense primer 5'-GCTTAGGCATAACGCACT-3'; Q-PCR GAPDH: sense primer $5^{\prime}$-CTCGTGGAGTCTACTGGTGT-3', antisense primer $5^{\prime}$-GTCATCATACTTGGCAGGTT-3').

\section{Quantitation of TNF- $\alpha$, IL-1 $\beta$, and IL-6}

TNF- $\alpha$ (Cloud Clone Corp, SEA133Mu), IL-1 $\beta$ (Cloud clone crop, SEA563Mu), and IL-6 (Cloud Clone Corp, SEA079Mu) levels in serum were analyzed using a capture enzymelinked immunoassay kit, in accordance with the manufacturer's instructions (Cloud Clone Corp).

\section{Data Analysis}

Statistical analysis was performed using Prism software version 7.0 (GraphPad Software, San Diego, CA, USA). Data are shown as means $\pm \mathrm{SD}$. Statistical significance was analyzed using oneway analysis of variance (ANOVA) followed by Tukey's multiple comparison tests. Error probabilities of $p<0.05$ were considered statistically significant.

\section{RESULTS}

\section{Characteristics of GD-scFv Isolated From Phage Display Libraries}

As shown in Figure 1A, our results indicate that we successfully purified the GD-scFv protein (about $30 \mathrm{Kd}$ ). We then used Beatty's equation for Kaff $\left[1 / 2\left(2\left[\mathrm{Ab}^{\prime}\right]_{\mathrm{t}}-[\mathrm{Ab}]_{\mathrm{t}}\right)\right.$, where $\left[\mathrm{Ab}^{\prime}\right]_{\mathrm{t}}$ refers to $\mathrm{GD}-\mathrm{scFv}$ concentration at half the maximal $\mathrm{OD}\left(\mathrm{OD}_{50}\right)$ for GD-coated wells at half concentration, and $[\mathrm{Ab}]_{\mathrm{t}}$ refers to GD-scFv concentration at $\mathrm{OD}_{450}$ for GD-coated wells at $100 \%$ concentration] to calculate the affinity of GD-scFv, and found that the Kd of GD-scFv was $4.25 \pm 2 \mathrm{nM}$ (Figure 1B). Moreover, the low binding reactivity of a non-specific IgG with GD-scFv suggested that GD-scFv possessed a high specificity on GD protein (Figure 1C).

\section{Evaluation of Properties of GD-mAb in vitro} Similar to GD-scFv, a high affinity $(3.13 \pm 0.89 \mathrm{nM})$ and a high specificity of GD-mAb for the GD protein was observed (Figures 2A,B). The plaque reduction neutralization test was used to test the sensitivity and the neutralizing effect on the virus. Our results indicate that the addition of GD-mAb reduces the plaque number in a concentration-dependent manner (Figures 2C,D).

\section{Effects of GD-mAb on Histopathology and Viral Replication in Lung Tissue}

To further evaluate the anti-RSV effect of GD-mAb, a mouse model was employed (Figure 3A). As shown in Figure 3B, both the treatment group (TL, TM, and TH) and the prevention group (PH and PL) significantly lowered lung index (lung wet weight/body weight) at $72 \mathrm{~h}$ after RSV infection. The $\mathrm{PH}$ group (0.85) showed the greatest effect, compared with the M group (1.21) $(p<0.01)$. In addition, we measured the lung virus titer in each group on days 3, 7, and 11, and found that both the treatment group (TL vs.TM vs. $\mathrm{TH}=4.3$ vs. 4.1 vs. 3.7 ) and the prevention group ( $\mathrm{PH}$ vs. $\mathrm{PL}=3.8$ vs. 3.9 ) showed a sound anti-RSV effect on day 3 compared with the M group (4.6). On day 7, GD-mAb in the treatment group and the prevention group had significantly decreased virus numbers, especially in groups $\mathrm{PH}$ and $\mathrm{TH}$ (1.2 vs. 1.5) compared with the $\mathrm{M}$ group (2.5) $(p<0.01)$. On day 11 no virus was detected in any group (Figure 3C).

\section{Effects of GD-mAb on the Inflammatory Status of the Lung}

As shown in Figure 4, severe inflammatory cell infiltration and obvious alveolar wall thickening was detected in group M (H\&E staining), while GD-mAb, especially in groups $\mathrm{PH}$ and $\mathrm{TH}$, had successfully restored lung tissues to their normal alveolar structure without significant pathological damage (Figure 4).

As some signaling pathways, e.g., Toll-like receptors (TLRs), NF- $\kappa \mathrm{B}$, MAPKs, and PI3K/AKT, have been reported to be involved in the inflammation cascade through pathogenassociated molecular pattern recognition. Therefore, the Western blot method was used to study the expression of key proteins in 
A

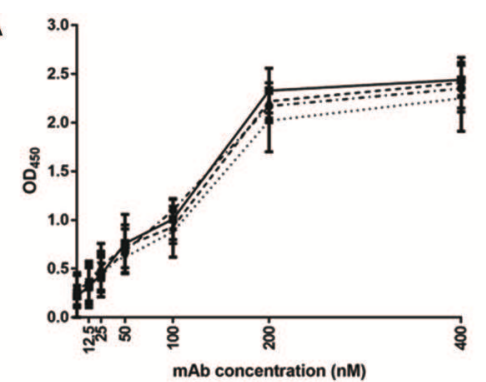

B
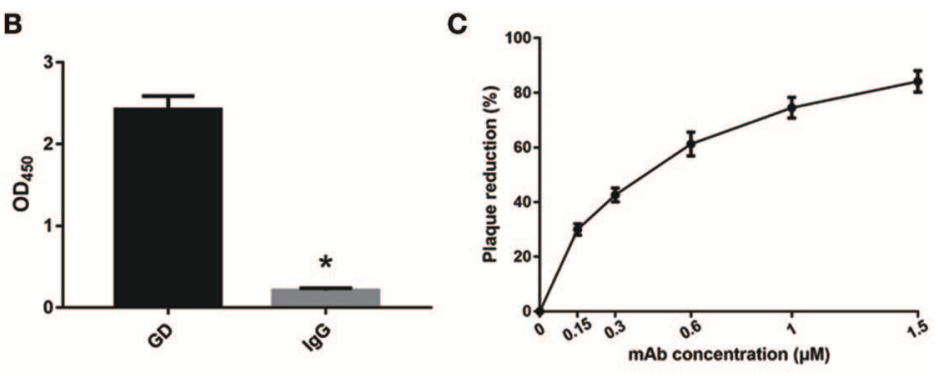

D Negative control Postive control

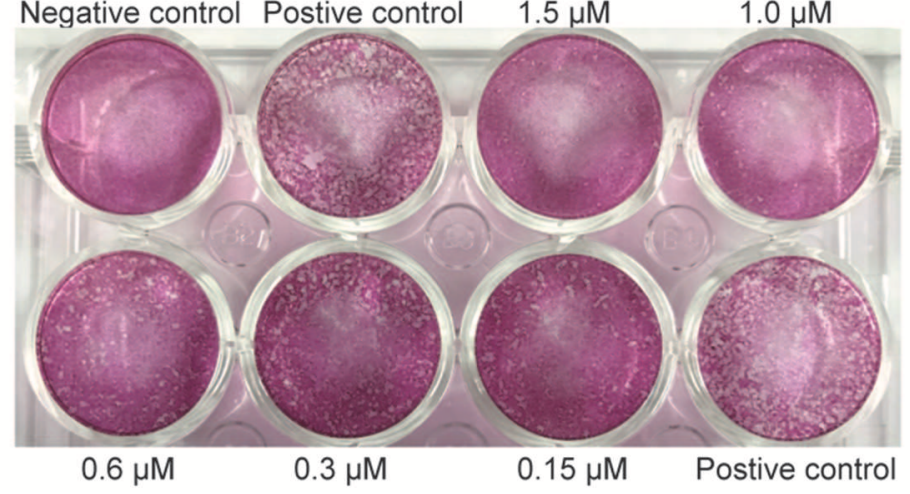

FIGURE 2 | Evaluation of properties of GD- mAb in vitro. (A) Measurement of GD- mAb using ELISA. The calculated Kd for mAb-GD was 4.01 nM using antigen concentrations of $2 \mu \mathrm{g} / \mathrm{ml}(-.$.$) and 1 \mu \mathrm{g} / \mathrm{ml}(-), 3.41 \mathrm{nM}$ using antigen concentrations of 1 and $0.5 \mu \mathrm{g} / \mathrm{ml}(---)$, or $2.23 \mathrm{nM}$ using antigen concentration of 0.5 and $0.25 \mu \mathrm{g} / \mathrm{ml}$ (...). (B) Evaluation of the specificity of GD- mAb using the ELISA method. (C,D) Evaluation of the neutralization effect of GD- mAb on respiratory virus using Vero cells. Results are presented as the mean $\pm \mathrm{SD}$. ${ }^{\star} P<0.05$ vs. control group.

these pathways. As shown in Figure 5, RSV infection significantly elevated inflammatory mediators of TLR4 (0.78), up-regulated pp65 expression (NF- $\mathrm{B}$ pathway) (0.83), p-ERK/p-p38 (MAPKs pathway) (0.43/0.72), and p-PI3K/p-AKT (PI3K/AKT pathway) $(0.66 / 0.92)$ in the $M$ group, while GD-mAb effectively inhibited further deterioration of the inflammatory response by reducing the phosphorylated protein level in the pathways of TLR4, NF- $\mathrm{B}$ (p-p65), p-ERK,p-p38, and p-PI3K, p-AKTin in groups TL (0.74 vs. 0.42 vs. 0.40 vs. 0.57 vs. 0.73 vs. 0.74$)$, TM ( 0.74 vs. 0.49 vs. 0.41 vs. 0.34 vs. 0.64 vs. 0.63$)$, TH (0.47 vs. 0.30 vs. 0.25 vs. 0.31 vs. 0.41 vs. 0.49$)$ and the prevention groups-PH (0.39 vs. 0.25 vs. 0.31 vs. 0.41 vs. 0.53 vs. 0.73$)$ and PL ( 0.43 vs. 0.29 vs. 0.42 vs. 0.44 vs. 0.47 vs. 0.60$)$ $(p<0.01$, Figure 5).

Finally, q-PCR and ELISA were used to investigate the release of TNF- $\alpha$, IL- $1 \beta$, and IL- 6 in the mouse lung and serum. Consistent with the previous results, RSV greatly induced the secretion of pro-inflammatory cytokines TNF- $\alpha$, IL- $1 \beta$, and IL6 in the $M$ group (1.85 vs. 2.72 vs. 2.14), while GD-mAb significantly suppressed the release of TNF- $\alpha$, IL-1 $\beta$, and IL- 6 in the lungs at gene level in the treatment group TL (1.25 vs. 2.17 vs. 1.80$)$, TM (1.16 vs. 1.91 vs. 1.67$)$, TH (1.10 vs. 1.84 vs. $1.62)$, the prevention group $\mathrm{PH}(1.07$ vs. 1.82 vs. 1.61$)$ and $\mathrm{PL}$ (1.19 vs. 1.90 vs. 1.78 ) compared with the M group. Similarly, GD-mAb also significantly inhibited the expression of these three pro-inflammatory factors in the treatment group TL (161.39 vs. 109.13 vs. 89.51$)$, TM (125.79 vs. 79.75 vs. 67.20$)$, TH (120.69 vs. 59.31 vs. 52.42$), \mathrm{PH}$ (114.57 vs. 59.00 vs. 48.51$)$ and PL
(128.14 vs. 65.42 vs. 56.50$)$ in the serum at the protein level $(p<0.01$, Figure 6).

\section{DISCUSSION}

RSV is still a common cause of lower respiratory tract disease and bronchiolitis in infants and young children worldwide. Up to the present day, only two FDA-approved drugs (ribavirin and palivizumab) are available for the specific prevention or treatment of RSV infection (Geevarghese and Simões, 2012). Ribavirin has limited efficacy and is seldomly used in immune compromised patients. Palivizumab is a monoclonal antibody for RSV infections in high-risk infants, and needs to be administered monthly at high cost (Yu et al., 2008). Currently, most licensed mAbs belong to chimeric or humanized mouse immunoglobulin molecules, and the allergic reactions caused by these mAbs (murine mAbs, human anti-chimeric antibody, and anti-humanized-antibody) lead to adverse outcomes and reduced their therapeutic efficacy (Stark et al., 2006; Wang et al., 2012; Guan et al., 2013). Thus, the development of fully human mAbs with more potent neutralizing activities remains a key goal for antibody research.

In the present study, phage display and antibody engineering were used to develop the GD-scFv and GD-mAb against RSV GD protein, and both these proteins showed a high affinity and high specificity to antigen GD (Figures 1, 2), while GD$\mathrm{mAb}$ also exhibited high neutralizing activity through plaque 


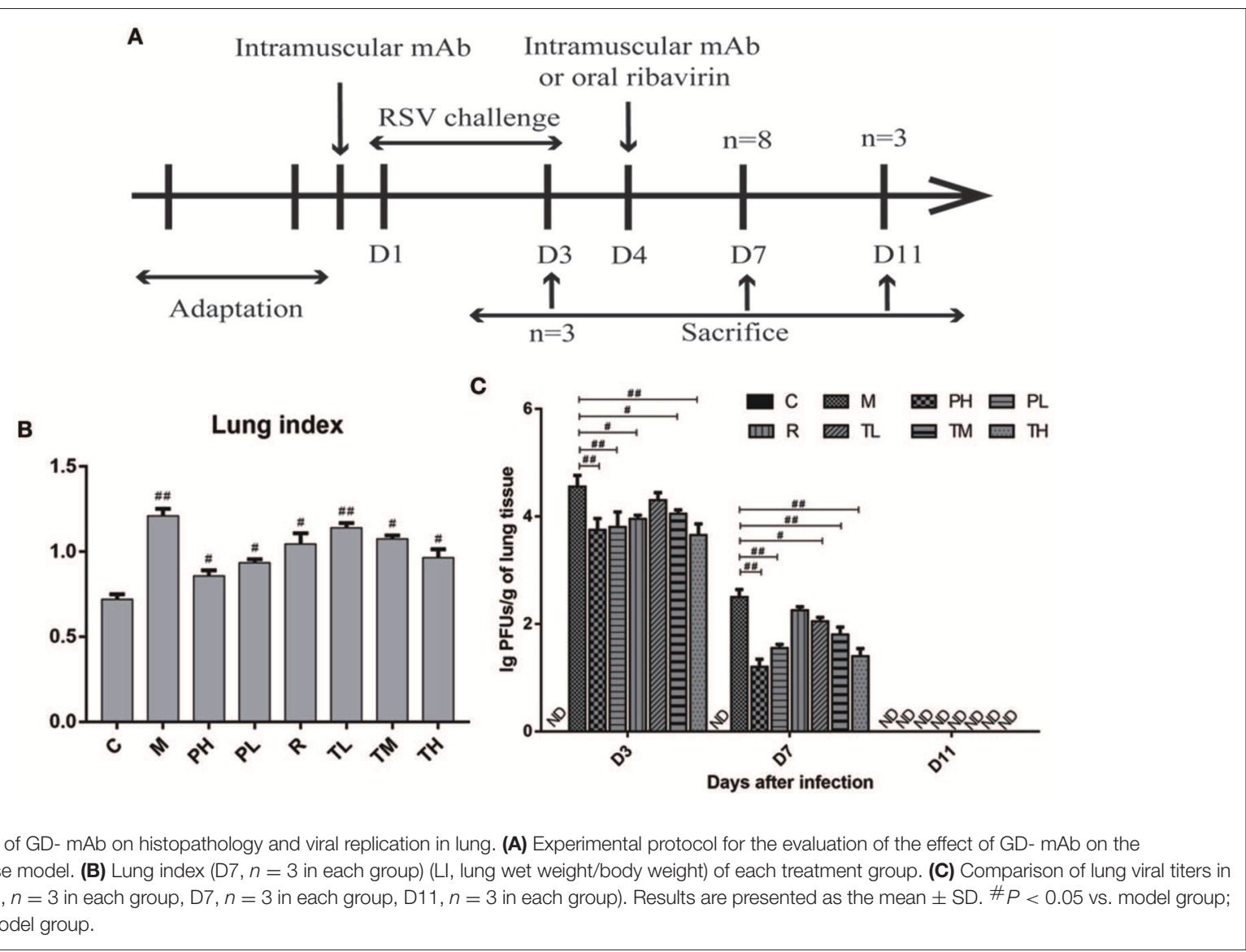

reduction virus neutralization assays in vitro (Figure 2). We report that high specificity and high affinity ensures the affinity of the antibody to find and combine to the target protein, and the high neutralizing activity ensures its high killing effects on the virus.

To further evaluate the therapeutic effect of GD-mAb, we employed a mouse model of RSV infection. Our results indicate that GD-mAb significantly decreases the pulmonary inflammatory response and decreases viral titer in the lungs by blocking cell attachment and intracellular replication (Shi et al., 2017), suppressing inflammatory cell infiltration and alleviating lung injury (Figures 3-6). Toll-like receptors (TLRs) are innate immune receptors expressed by immune cells, and they are positioned as a first line of innate defense by recognizing pathogen-associated molecular patterns as well as endogenous signals of tissue injury (Nahid et al., 2011; Steensma et al., 2014). In previous studies, researchers found that the increase of TLR4 on the cell surface plays a fundamental role in regulating the immune response against RSV infection. Moreover it could activate NF- $\mathrm{kB}$ members (Kurt-Jones et al., 2000; Monick et al., 2003; Gagro et al., 2004), involving the expression and release of several cytokines and chemokines that were regulated by NF-кB. Furthermore, a recent study has shown that RSV activation of p38 in mitogen-activated protein kinase pathways (MAPKs) in a TLR4 mediated manner during the early stage of infection, utilized p38 to enter the cell for replication (Marchant et al., 2010). Researches demonstrated that PI3K/AKT could regulate the activation of multiple intracellular signaling cascades and is a function of many inflammatory mediators (Xuan et al., 2017). TLR4, MAPKs and P13K/ATK could also lead to an increase in the nuclear translocation and transcriptional activity of NF- $\mathrm{\kappa B}$ (Hattori et al., 2003; Capiralla et al., 2012). When the NF- $\mathrm{B}$ pathway was activated, massive amounts of pro-inflammatory cytokines (e.g., TNF- $\alpha$, IL- $1 \beta$, and IL-6) were released, which were strongly associated with the outcome of inflammatory disease (Ren et al., 1996). In our work, RSV infection greatly enhances the yield of TLR4, phosphorylated protein p38, ERK, PI3K, and AKT in the MAPKs and PI3K/Akt pathways, which then promotes the phosphorylated protein p65 (NF- $\mathrm{kB}$ pathway), while GD-mAb effectively inhibits the further deterioration of the inflammatory response by reducing their phosphorylation in lung (Figures 5, 6).

In addition, accumulating evidence indicates that viral invasion involves the production of a plethora of cytokines, chemokines, and immune modulatory mediators, including TNF- $\alpha$, IL-1 $\beta$, and IL-6 which can strongly influence inflammatory responses. As we know, TNF- $\alpha$ is an important inflammatory cytokine in the development of lung inflammation and higher levels of TNF- $\alpha$ are associated with chronic 


\section{A}

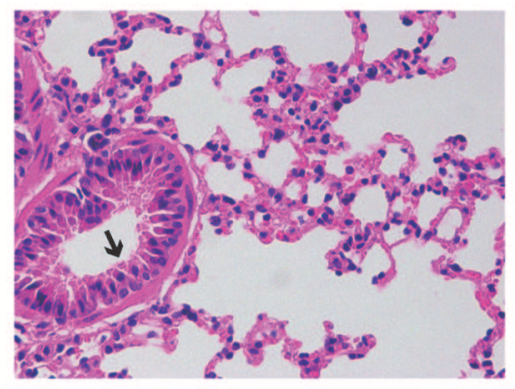

B

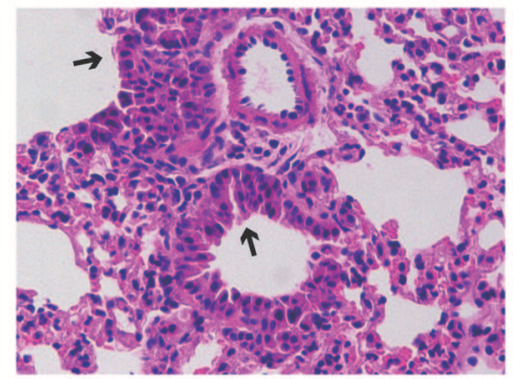

C

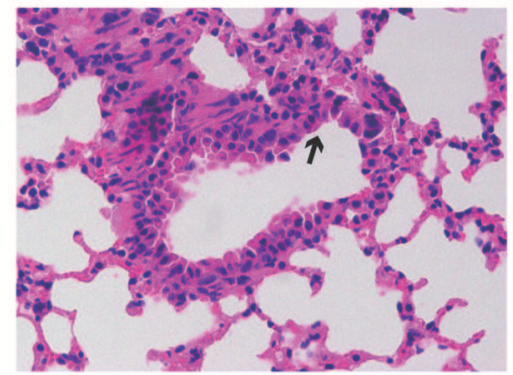

D

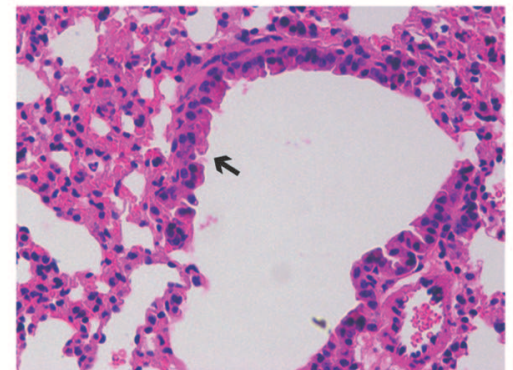

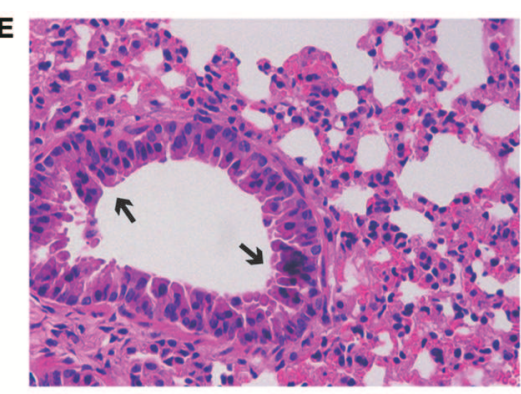

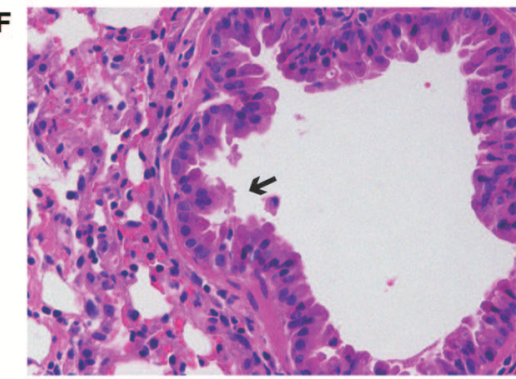

G

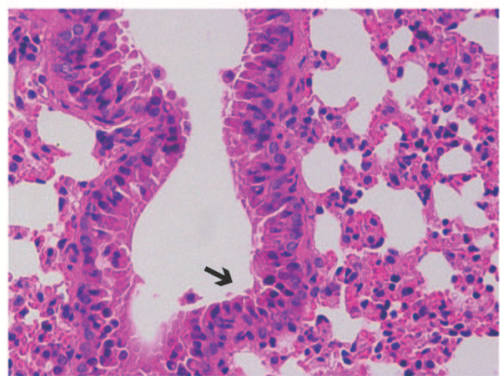

H

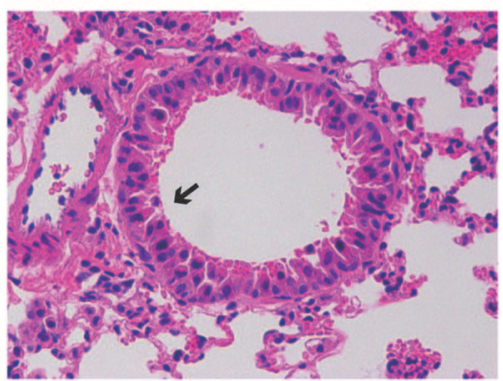

FIGURE 4 | Effects of GD- mAb on RSV-induced histological changes in lung tissues using H\&E method (magnification 200 $\times$ ) (D7, $n=3$ in each group). (A-H) $\mathrm{C}$ group, M group, PH group, PL group, R group, TL group, TM group, and TH group.

obstructive pulmonary disease (Lewis, 2007; Luo et al., 2017). IL- $1 \beta$ is a crucial inflammatory factor involved in pneumonia and research indicates that the level of IL-1 $\beta$ in the lungs of chronic obstructive pulmonary disease patients is higher than that of non-smokers (Pauwels and Rabe, 2004). In addition, studies indicate that a benefit is obtained when the IL- 6 response is suppressed in mice challenged with RSV. Therefore, the low expression of TNF- $\alpha$, IL- $1 \beta$, and IL- 6 in mice in the pre-treated and treated groups indicate that GD-mAb is beneficial in reducing inflammation in RSV-infected mice.

Our data indicate that the anti-RSV GD-mAb possesses a high affinity and high specificity with the GD protein, and can effectively neutralize RSV in vitro. The animal results further indicate that GD-mAb can significantly lower the lung index and reduce the lung virus titer in mouse lungs and effectively reduce the phosphorylated protein level in pathways of TLR4/NF- $\mathrm{B}, \mathrm{MAPKs}$, and PI3K/Akt, which inhibit the release of pro-inflammatory factors TNF- $\alpha$, IL$1 \beta$, and IL- 6 in mouse serum and lungs. These findings suggest that GD-mAb may be a potential agent for the prevention and treatment of RSV infection. However, the qualitative results of $\mathrm{H} \& \mathrm{E}$ staining, the semiquantitative assays of Western blotting, and the absence of a positive control (e.g., Palivizumab) reduce the reliability of our work, and further 

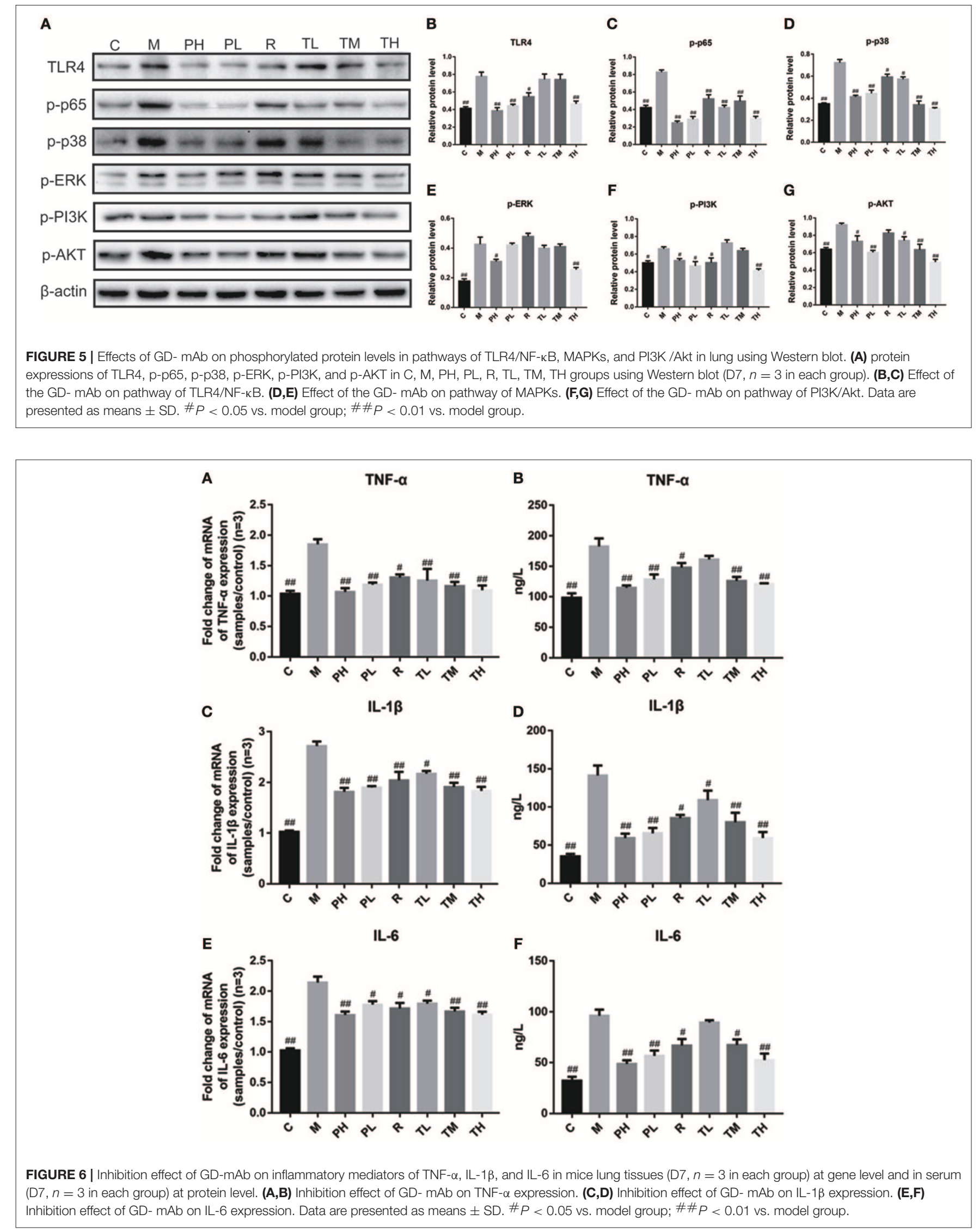
work is needed to explore the actual effect of GD-mAb on RSV infection.

\section{ETHICS STATEMENT}

The present study was approved by the Ethical Committee of the Second Affiliated Hospital of Nanchang University (Nanchang, China) and all methods were performed in accordance with the approved guidelines.

\section{AUTHOR CONTRIBUTIONS}

TC designed the experiment. PT, YW, HL, YY, XW, and HW performed the experiments. TC and PT analyzed the data and

\section{REFERENCES}

Capiralla, H., Vingtdeux, V., Zhao, H., Sankowski, R., Al-Abed, Y., Davies, P., et al. (2012). Resveratrol mitigates lipopolysaccharide- and Abeta-mediated microglial inflammation by inhibiting the TLR4/NF-kappaB/STAT signaling cascade. J. Neurochem. 120, 461-472. doi: 10.1111/j.1471-4159.2011.07594.x

DeVincenzo, J. P., Whitley, R. J., Mackman, R. L., Scaglioni-Weinlich, C., Harrison, L., Farrell, E., et al. (2014). Oral GS-5806 activity in a respiratory syncytial virus challenge study. N. Engl. J. Med. 371, 711-722. doi: 10.1056/NEJMoa1401184

Fauci, A. S., Johnston, M. I., Dieffenbach, C. W., Burton, D. R., Hammer, S. M., Hoxie, J. A., et al. (2008). HIV vaccine research: the way forward. Science 321, 530-532. doi: 10.1126/science.1161000

Gagro, A., Tominac, M., Krsulović-Hresić, V., Baće, A., Matić, M., Drazenović, V., et al. (2004). Increased Toll-like receptor 4 expression in infants with respiratory syncytial virus bronchiolitis. Clin. Exp. Immunol. 135, 267-272. doi: $10.1111 / j .1365-2249.2004 .02364 . x$

Geevarghese, B., and Simões, E. A. (2012). Antibodies for prevention and treatment of respiratory syncytial virus infections in children. Antivir. Ther. 17, 201-211. doi: 10.3851/IMP2061

Guan, Y., Pazgier, M., Sajadi, M. M., Kamin-Lewis, R., Al-Darmarki, S., Flinko, R., et al. (2013). Diverse specificity and effector function among human antibodies to HIV-1 envelope glycoprotein epitopes exposed by CD4 binding. Proc. Natl. Acad. Sci. U.S.A. 110, E69-E78. doi: 10.1073/pnas.1217609110

Hattori, Y., Hattori, S., and Kasai, K. (2003). Lipopolysaccharide activates Akt in vascular smooth muscle cells resulting in induction of inducible nitric oxide synthase through nuclear factor-kappa B activation. Eur. J. Pharmacol. 481, 153-158. doi: 10.1016/j.ejphar.2003.09.034

Haynes, L. M., Caidi, H., Radu, G. U., Miao, C., Harcourt, J. L., Tripp, R. A., et al. (2009). Therapeutic monoclonal antibody treatment targeting respiratory syncytial virus (RSV) G protein mediates viral clearance and reduces the pathogenesis of RSV infection in BALB/c mice. J. Infect. Dis. 200, 439-447. doi: $10.1086 / 600108$

Haynes, L. M., Tonkin, J., Anderson, L. J., and Tripp, R. A. (2002). Neutralizing anti-F glycoprotein and anti-substance $\mathrm{P}$ antibody treatment effectively reduces infection and inflammation associated with respiratory syncytial virus infection. J. Virol. 76, 6873-6881. doi: 10.1128/JVI.76.14.6873-6881.2002

Hu, H., Luo, L., Liu, F., Zou, D., Zhu, S., Tan, B., et al. (2016). Anti-cancer and sensibilisation effect of triptolide on human epithelial ovarian cancer. J. Cancer 7, 2093-2099. doi: 10.7150/jca.16178

Huang, J., Doria-Rose, N. A., Longo, N. S., Laub, L., Lin, C. L., Turk, E., et al. (2013). Isolation of human monoclonal antibodies from peripheral blood B cells. Nat. Protoc. 8, 1907-1915. doi: 10.1038/nprot.2013.117

Kurt-Jones, E. A., Popova, L., Kwinn, L., Haynes, L. M., Jones, L. P., Tripp, R. A., et al. (2000). Pattern recognition receptors TLR4 and CD14 mediate response to respiratory syncytial virus. Nat. Immunol. 1, 398-401. doi: 10.1038/80833

Lewis, G. K. (2007). Live-attenuated Salmonella as a prototype vaccine vector for passenger immunogens in humans: are we there yet? Expert Rev. Vaccines 6, 431-440. doi: 10.1586/14760584.6.3.431 wrote the manuscript. All authors discussed the results and commented on the manuscript.

\section{FUNDING}

This work was supported by grants from the National Natural Science Foundation of China (No. 31560264), the Excellent Youth Foundation of Jiangxi Scientific Committee (No. 20171BCB23028), the Key R\&D plan of JiangXi Science and Technology Agency (No. 20181BBG70028), the JiangXi Provincial Science and Technology innovation team (No. 20181BCB24003) and the Science and Technology plan of Jianxi Health Planning Committee (No. 20175526).

Luo, F., Liu, J., Yan, T., and Miao, M. (2017). Salidroside alleviates cigarette smoke-induced COPD in mice. Biomed. Pharmacother. 86, 155-161. doi: 10.1016/j.biopha.2016.12.032

Marchant, D., Singhera, G. K., Utokaparch, S., Hackett, T. L., Boyd, J. H., Luo, Z., et al. (2010). Toll-like receptor 4-mediated activation of p38 mitogen-activated protein kinase is a determinant of respiratory virus entry and tropism. J. Virol. 84, 11359-11373. doi: 10.1128/JVI.00804-10

McLellan, J. S. (2015). Neutralizing epitopes on the respiratory syncytial virus fusion glycoprotein. Curr. Opin. Virol. 11, 70-75. doi: 10.1016/j.coviro.2015.03.002

Monick, M. M., Yarovinsky, T. O., Powers, L. S., Butler, N. S., Carter, A. B., Gudmundsson, G., et al. (2003). Respiratory syncytial virus up-regulates TLR4 and sensitizes airway epithelial cells to endotoxin. J. Biol. Chem. 278, 53035-53044. doi: 10.1074/jbc.M308093200

Murawski, M. R., McGinnes, L. W., Finberg, R. W., Kurt-Jones, E. A., and Massare, M. J., Smith, G., et al. (2010). Newcastle disease virus-like particles containing respiratory syncytial virus $\mathrm{G}$ protein induced protection in BALB/c mice, with no evidence of immunopathology. J. Virol. 84, 1110-1123. doi: 10.1128/JVI.01709-09

Murray, J., Saxena, S., and Sharland, M. (2014). Preventing severe respiratory syncytial virus disease: passive, active immunisation and new antivirals. Arch. Dis. Child. 99, 469-473. doi: 10.1136/archdischild-2013-303764

Nahid, M. A., Satoh, M., and Chan, E. K. (2011). MicroRNA in TLR signaling and endotoxin tolerance. Cell Mol. Immunol. 8, 388-403. doi: 10.1038/cmi.2011.26

Pauwels, R. A., and Rabe, K. F. (2004). Burden and clinical features of chronic obstructive pulmonary disease (COPD). Lancet 364, 613-620. doi: 10.1016/S0140-6736(04)16855-4

Ren, Z. J., Lewis, G. K., Wingfield, P. T., Locke, E. G., Steven, A. C., and Black, L. W. (1996). Phage display of intact domains at high copy number: a system based on SOC, the small outer capsid protein of bacteriophage T4. Protein Sci. 5, 1833-1843. doi: 10.1002/pro.55600 50909

Shi, T., Mcallister, D. A., O’brien, K. L., Simoes, E. A., Madhi, S. A. F., Gessner, B. D., et al. (2017). Global, regional, and national disease burden estimates of acute lower respiratory infections due to respiratory syncytial virus in young children in 2015: a systematic review and modelling study. Lancet 390, 946-958. doi: 10.1016/S0140-6736(17)30938-8

Stark, J. M., Stark, M. A., Colasurdo, G. N., and LeVine, A. M. (2006). Decreased bacterial clearance from the lungs of mice following primary respiratory syncytial virus infection. J. Med. Virol. 78, 829-838. doi: 10.1002/jmv.20631

Steensma, D. P., Shampo, M. A., and Kyle, R. A. (2014). Bruce Beutler: innate immunity and Toll-like receptors. Mayo Clin. Proc. 89:e101. doi: 10.1016/j.mayocp.2013.10.039

Tian, P., Xu, D., Huang, Z., Meng, F., Fu, J., Wei, H., et al. (2018). Evaluation of truncated $\mathrm{G}$ protein delivered by live attenuated Salmonella as a vaccine against respiratory syncytial virus. Microb. Pathog. 115, 299-303. doi: 10.1016/j.micpath.2017.12.080 
Tiller, T., Meffre, E., Yurasov, S., Tsuiji, M., Nussenzweig, M. C., and Wardemann, H. (2008). Corrigendum to 'Efficient generation of monoclonal antibodies from single human B cells by single cell RT-PCR and expression vector cloning'[J. Immunol. Methods 329 (2008) 112-124]. J. Immunol. Methods 334, 142. doi: $10.1016 /$ j.jim.2008.02.010

Tripp, R. A. (2004). Pathogenesis of respiratory syncytial virus infection. Viral Immunol. 17, 165-181. doi: 10.1089/0882824041310513

Varga, S. M., and Braciale, T. J. (2002). RSV-induced immunopathology: dynamic interplay between the virus and host immune response. Virology 295, 203-207. doi: 10.1006/viro. 2002.1382

Wang, H. M., Xu, K., Yu, S. Q., Ding, L. L., Luo, H. Y., Flinko, R., et al. (2012). [Identification of Env-specific monoclonal antibodies from Chinese HIV-1 infected person by B cell activation and RT-PCR cloning]. Chin. J. Virol. 28:358.

Weinberg, G. A. (2017). Respiratory syncytial virus mortality among young children. Lancet Glob. Health 5, e951-e952. doi: 10.1016/S2214-109X(17) 30348-0

Xuan, F., Jian, J., Lin, X., Huang, J., Jiao, Y., Huang, W., et al. (2017), 17-methoxyl-7-hydroxy-benzene-furanchalcone ameliorates myocardial ischemia/reperfusion injury in rat by inhibiting apoptosis and autophagy via the PI3K-Akt signal pathway. Cardiovasc. Toxicol. 17, 79-87. doi: 10.1007/s12012-016-9358-y

Yu, X., Tsibane, T., Mcgraw, P. A., House, F. S., Keefer, C. J., Hicar, M. D., et al. (2008). Neutralizing antibodies derived from the B cells of 1918 influenza pandemic survivors. Nature 455, 532-536. doi: 10.1038/nature07231

Zeng, C., Chen, T., Zhang, Y., and Chen, Q. (2017). Hedgehog signaling pathway regulates ovarian cancer invasion and migration via adhesion molecule CD24. J. Cancer 8, 786-792. doi: 10.7150/jca.17712

Conflict of Interest Statement: The authors declare that the research was conducted in the absence of any commercial or financial relationships that could be construed as a potential conflict of interest.

Copyright (C) 2019 Tian, Wang, Liu, Yang, Wu, Wei and Chen. This is an open-access article distributed under the terms of the Creative Commons Attribution License (CC $B Y)$. The use, distribution or reproduction in other forums is permitted, provided the original author(s) and the copyright owner(s) are credited and that the original publication in this journal is cited, in accordance with accepted academic practice. No use, distribution or reproduction is permitted which does not comply with these terms. 